Article

\title{
A Thin Film Nanocomposite Membrane with MCM-41 Silica Nanoparticles for Brackish Water Purification
}

\author{
Mohammed Kadhom ${ }^{1}$, Jun Yin ${ }^{2}$ and Baolin Deng ${ }^{1,2, *}$ \\ 1 Department of Chemical Engineering, University of Missouri, Columbia, MO 65211, USA; \\ makbq6@mail.missouri.edu \\ 2 Department of Civil and Environmental Engineering, University of Missouri, Columbia, MO 65211, USA; \\ jy3d9@mail.missouri.edu \\ * Correspondence: dengb@missouri.edu; Tel.: +1-573-882-0075
}

Academic Editor: Klaus Rätzke

Received: 30 October 2016; Accepted: 29 November 2016; Published: 6 December 2016

\begin{abstract}
Thin film nanocomposite (TFN) membranes containing MCM-41 silica nanoparticles (NPs) were synthesized by the interfacial polymerization (IP) process. An $m$-phenylenediamine (MPD) aqueous solution and an organic phase with trimesoyl chloride (TMC) dissolved in isooctane were used in the IP reaction, occurring on a nanoporous polysulfone (PSU) support layer. Isooctane was introduced as the organic solvent for TMC in this work due to its intermediate boiling point. MCM-41 silica NPs were loaded in MPD and TMC solutions in separate experiments, in a concentration range from 0 to $0.04 \mathrm{wt} \%$, and the membrane performance was assessed and compared based on salt rejection and water flux. The prepared membranes were characterized via scanning electron microscopy (SEM), transmission electron microscopy (TEM), contact angle measurement, and attenuated total reflection Fourier transform infrared (ATR FT-IR) analysis. The results show that adding MCM-41 silica NPs into an MPD solution yields slightly improved and more stable results than adding them to a TMC solution. With $0.02 \%$ MCM-41 silica NPs in the MPD solution, the water flux was increased from 44.0 to $64.1 \mathrm{~L} / \mathrm{m}^{2} \cdot \mathrm{h}$, while the rejection virtually remained the same at $95 \%$ (2000 ppm NaCl saline solution, $25^{\circ} \mathrm{C}, 2068 \mathrm{kPa}(300 \mathrm{psi})$ ).
\end{abstract}

Keywords: reverse osmosis (RO); thin film nanocomposite (TFN) membrane; MCM-41 nanoparticles (NPs)

\section{Introduction}

Because of the rapid increase in human population in the last decades, the demand for fresh water has dramatically increased [1]. Desalination of sea and brackish water represents a major approach to supply fresh water for drinking and for agricultural and industrial applications [2]. Many large-scale desalination plants have been built around the world in recent years, and this trend is anticipated to continue $[1,3]$. Reverse osmosis $(\mathrm{RO})$ is the most frequently selected desalination process for new desalination capacity buildup because of its reliability, inexpensiveness, and greenness [4]. Many studies have been conducted to improve the RO process and reduce energy consumption $[1,4]$.

A thin film composite (TFC) membrane has been commonly used for desalination since it was developed 35 years ago [5]. It is mostly made via the interfacial polymerization of $m$-phenylenediamine (MPD) and trimesoyl chloride (TMC) on a polysulfone (PSU) or polyethersulfone (PES) support layer $[5,6]$. TFCs with other support such as modified polyvinylidene fluoride (PVDF) have also been developed [7].

Recently, an active effort has been devoted to develop thin film nanocomposite (TFN) membranes in which nano-sized additives are incorporated. Some nano additives have been found to improve 
membranes properties [8], particularly, hydrophilic nanomaterials [9,10]. For instance, hydrophilic zeolite particles have been shown to improve water permeation flux and decrease the contact angle. Zeolite nanoparticles (NPs) are assumed to have narrow pores that can allow the water to pass through and reject salt ions [11-16]; however, the magnitude of water flux capable of passing through very small micropores $(<1 \mathrm{~nm})$ needs to be further examined. Titanium dioxide $\left(\mathrm{TiO}_{2}\right)$ was shown to enhance water flux as well when it was used in membrane manufacturing; in particular, when it is exposed to UV light, $\mathrm{TiO}_{2}$ becomes a superhydrophilic material [17]. Many researchers have added $\mathrm{TiO}_{2}$ NPs to TFNs in different forms [18-21]. Moreover, metal-organic frameworks (MOFs) have been used as fillers in different membrane applications, specifically for gas separation and purification [22].

Silica NPs have been injected as hydrophilic fillers in membranes and their support sheets, and have shown remarkable effects in both cases [8,23-26]. In a previous study by our group, two types of MCM-41 silica NPs were prepared-porous and non-porous-and it was demonstrated that porous MCM-41 silica NPs with internal pores of approximately $3 \mathrm{~nm}$ yielded better results than the non-porous one. By adding porous silica NPs, the water flux was significantly increased with almost no change in salt rejection. This is attributed to the enhancement of the membrane's surface hydrophilicity and the short flow paths through the mesoporous structure [8].

In this work, porous MCM-41 silica NPs approximately $100 \mathrm{~nm}$ in diameter were added to either MPD or TMC solutions, and their impacts on the membrane performance were investigated. Different weight ratios of the fillers to the solutions were used. Additionally, for the first time, isooctane (2,2,4-Trimethylpentane), an organic solvent that has lower volatility than hexane and is safer to work with, was used to prepare the TMC solution. Contact angle, scanning electron microscopy, transmission electron microscopy, and attenuated total reflection Fourier transform infrared spectroscopy were used to characterize the membrane's physicochemical properties.

\section{Materials and Methods}

\subsection{Materials}

Tetraethyl orthosilicate (TEOS, 98\%, Sigma-Aldrich, St. Louis, MO, USA) and cetyltrimethylammonium bromide (CTAB, 95\%, Aldrich) were used as silica raw material and surfactant, respectively, to prepare MCM-41 NPs. 2,2,4-Trimethylpentane (isooctane, 99\%) was obtained from Fisher Scientific (Pittsburgh, PA, USA). Triethylamine (TEA, $\geq 99 \%$ ) and (1s)-(+)-10-camphorsulfonic acid (CSA, 99\%) used in CSA/TEA salt synthesis were purchased from Sigma-Aldrich. Sodium hydroxide $(\mathrm{NaOH})$ and calcium chloride $\left(\mathrm{CaCl}_{2}\right)$ were obtained from Fisher Scientific. The casting solution used to make the PSU support layer was prepared by dissolving polysulfone pellets (PSU, $M_{W}=35,000$, Sigma-Aldrich) in N,N-dimethylformamide (DMF, 99.8\%, Sigma-Aldrich). $m$-Phenylenediamine (MPD, $\geq 99 \%$, Fisher) and trimesoyl chloride (TMC, $\geq 98.5 \%$, Sigma-Aldrich) were used in membrane preparation. The Millipore DI water $(18.2 \mathrm{M} \Omega \cdot \mathrm{cm}$, produced by Synergy 185, EMD Millipore Corp., Billerica, MA, USA) was used to prepare solutions and for rinsing and cleaning.

\subsection{Preparation and Characterization of MCM-41 NPs}

The MCM-41 NP preparation procedure has been reported in the literature [27]: $3.5 \mathrm{~mL}$ of a $2 \mathrm{M}$ $\mathrm{NaOH}$ solution was added to $480 \mathrm{~mL}$ of DI water and mixed well for $10 \mathrm{~min}$. Then, the solution was heated to $353 \mathrm{~K}$, and $1.0 \mathrm{~g}$ of CTAB was added and mixed for $30 \mathrm{~min}$. Next, $5 \mathrm{~mL}$ of TEOS was added drop by drop, and the mixture was left to stir. After $2 \mathrm{~h}$, a white slurry was formed. The mixture was centrifuged (Eppendorf, Hamburg, Germany, centrifuge 5810 R) for $10 \mathrm{~min}$ at 10,000 rpm under a temperature of $20^{\circ} \mathrm{C}$, and the solid product was washed and centrifuged again twice. The product was collected, left to dry at room temperature, and then calcinated in a furnace for $4 \mathrm{~h}$ at $823 \mathrm{~K}$. 


\subsection{Preparation of PSU Support Layer Sheets}

The PSU sheets were manufactured using the phase inversion phenomenon. The casting solution was prepared by dissolving $15 \mathrm{wt} \%$ of PSU in a DMF solvent and heating to $60{ }^{\circ} \mathrm{C}$ under stirring for $5 \mathrm{~h}$. A clear solution thus formed was kept overnight for degassing. The membrane sheets were fabricated by spreading the solution on a glass plate and casting by a casting knife (EQ-Se-KTQ-150, MTI Corp., Richmond, CA, USA) to a $120 \mu \mathrm{m}$ thickness. The glass plate was immersed in DI water quickly, and the PSU sheet was formed. The as-prepared membrane sheets were washed several times and stored in DI water for $24 \mathrm{~h}$ at $4{ }^{\circ} \mathrm{C}$ before use.

\subsection{Preparation of Thin Film Nanocomposite Membrane}

The PSU support sheet was first placed on a flat glass plate, on which the residual water was removed by a squeegee roller, and then soaked in the amine solution for $20 \mathrm{~s}$. The aqueous amine solution consisted of $2 \mathrm{wt} \% \mathrm{MPD}, 1 \mathrm{wt} \% \mathrm{CSA} / \mathrm{TEA}$ salt, and $0.01 \mathrm{wt} \% \mathrm{CaCl}_{2}$, all dissolved in Millipore water. The excess amine solution on the membrane was removed using the squeegee roller. The membrane sheet was left to dry for $3.5 \mathrm{~min}$ at ambient temperature, and then immersed in $0.14 \mathrm{wt} \% \mathrm{TMC}$ in an isooctane solution for $15 \mathrm{~s}$ to create the polyamide thin film membrane. The sheet was dried in the oven for $6 \mathrm{~min}$ at $80^{\circ} \mathrm{C}$ and stored in DI water at $4{ }^{\circ} \mathrm{C}$ until use.

MCM-41 silica NPs were added to the MPD or TMC solutions, in separate experiments, at different weight ratios varying from 0 to $0.04 \mathrm{wt} \%$. When the NPs were added to the TMC solution, it was necessary to sonicate the mixture for $1 \mathrm{~h}$ to achieve full dispersion, while shaking for $15 \mathrm{~s}$ was enough when they were added to the MPD solution.

\subsection{TFN Membrane Characterization}

Membrane morphology was examined using SEM (Quanta FEG 600, FEI Company, Hillsboro, OR, USA). The samples were dried at ambient temperature and stored at $4{ }^{\circ} \mathrm{C}$ until the test. The membrane samples were coated with platinum using a sputter coater (K575x, Emitech Ltd., Kent, UK) at 20 mA for $1 \mathrm{~min}$ to make them conductive for SEM. Different voltage intensities were used depending on the image magnification.

Images of the membrane's cross-sectional view were taken using a TEM device (JEOL 1400, JEOL Ltd., Peabody, MA, USA). The samples were prepared by immersing the membrane sheets in resin (Eponate 12, Ted Pella, Inc., Redding, CA, USA) and drying. The samples were then cut by Reichert-Jung Ultra cut E ultramicrotome (Reichert, Inc., Depew, NY, USA).

The membrane surface functional groups were detected using attenuated total reflection Fourier transform infrared spectroscopy. A Nicolet 4700 FT-IR (Thermo Electron Corporation, Waltham, MA, USA) system with a multi-reflection smart performer ATR accessory was employed. The collected spectra were from 500 to $4000 \mathrm{~cm}^{-1}$ with a 64 scanning rate at a $2.0 \mathrm{~cm}^{-1}$ resolution.

The hydrophilicity of the membranes was evaluated by measuring the surface contact angle of DI water. A contact angle video system (VCA-2500 XE, AST products, Billerica, MA, USA) was used for this purpose using a sessile drop method. The measurements were repeated at least six times at different locations of the membrane, and the standard deviation was assessed for the results.

The water flux and salt rejection were measured via a cross-flow filtration system, as illustrated in Figure 1.

The membrane sheet was put in a filter holder (Model: XX4504700, stainless steel, Millipore Corp., Billerica, MA, USA) and tested under $2068 \mathrm{kPa}$ operation pressure for approximately eight hours. The permeate water flux was measured by the weight accumulation in time using LABVIEW software (National Instruments LabVIEW 8.2 with Ohaus digital balance). The water flux was calculated with Equation (1).

$$
J=\frac{V}{\mathrm{~A} \times \mathrm{t}}
$$


where $J$ is the water flux $\left(\mathrm{L} / \mathrm{m}^{2} \cdot \mathrm{h}\right), V$ the product volume, A the membrane area, and $\mathrm{t}$ the accumulation time.

The salt rejection of the brackish water used in this work (2000 ppm NaCl) was estimated by measuring the conductivity of the total dissolved salts using a conductivity meter (HACH Company, Loveland, CO, USA). The measurements were taken at $25^{\circ} \mathrm{C}$, and the rejection was calculated using Equation (2).

$$
\mathrm{R}=\left(1-\frac{C_{p}}{C_{f}}\right) \times 100
$$

where $\mathrm{R}$ is the salt rejection ratio, $C_{p}$ the permeate conductivity, and $C_{f}$ the feed conductivity.

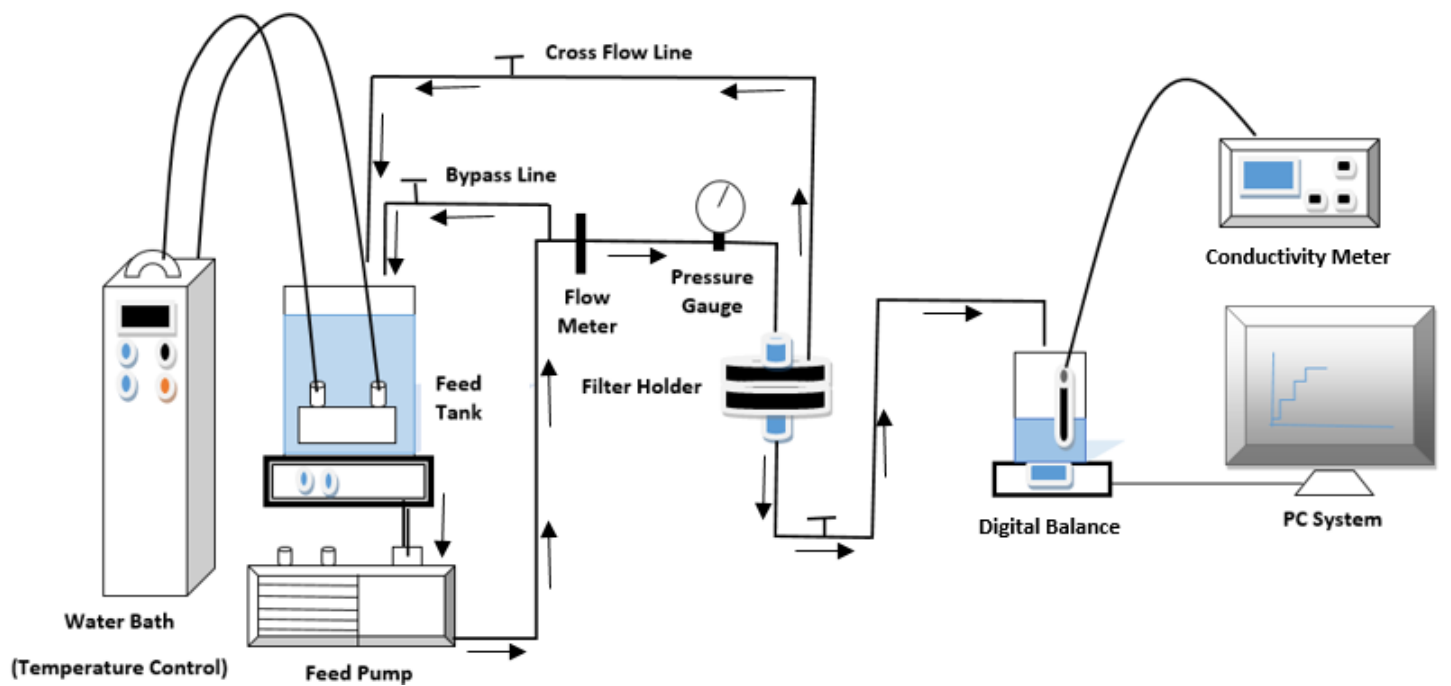

Figure 1. Graphical diagram of the desalination system.

\section{Results and Discussion}

\subsection{Characterizations of MCM- 41 NPs}

XRD patterns, pore size distribution, the $\mathrm{N}_{2}$ adsorption/desorption isotherm, SEM, and TEM have been reported for porous MCM-41 NPs in a previous research in our group [8].

\subsection{TFN Membrane Characterizations}

This study selected 2,2,4-trimethylpentane, also named isooctane, as an organic solvent for TMC. It was used for its intermediate boiling point, low volatility, and lesser health impact, so that the common solvent evaporation problem associated with membrane synthesis could be solved. For comparison, Table 1 presents the properties of isooctane and the traditionally used solvent, hexane [28-31]. The key is to ensure that the membrane quality could be maintained when hexane is replaced by isooctane.

Table 1. A comparison of physical properties between isooctane and hexane.

\begin{tabular}{ccc}
\hline Property & Isooctane & Hexane \\
\hline Boiling Point $\left({ }^{\circ} \mathrm{C}\right)$ & 99 & 69 \\
Flash Point $\left({ }^{\circ} \mathrm{C}\right)$ & -12 & -26 \\
Evaporation Rate & 1 & 15.8 \\
Vapor Pressure $(\mathrm{mmHg})$ & $88\left(\right.$ at $\left.37.80{ }^{\circ} \mathrm{C}\right)$ & $256\left(\right.$ at $\left.37.70{ }^{\circ} \mathrm{C}\right)$ \\
Vapor Density $(\mathrm{Air}=1)$ & 3.94 & 2.97 \\
Relative Density $\left(\mathrm{g} / \mathrm{cm}^{3}\right)$ & 0.690 & 0.659 \\
Health Hazard & Less & Higher \\
\hline
\end{tabular}


The surface morphology was investigated using SEM. The TFC and TFN membrane morphology with loaded NPs at different percentages are illustrated in Figure 2. It is noted that the control membrane, obtained by the IP reaction between TMC and MPD without additives on a PSU layer, has a leaf-like morphology, Figure 2a, typical of TFC. Adding NPs in different loadings did not change the general structure of the membranes (Figure $2 b-i$ ). The added NPs to the TMC solution can be observed as spherical particles within the membrane structure, or by morphology change (Figure 2b-g). By increasing the NP loading, the amount of NPs in the membranes was increased and eventually started to aggregate, as shown in Figure $2 \mathrm{~g}$. As is evident from the SEM images, the NPs in the membranes when added via the MPD solution are not as visible as those when the NPs were introduced via the TMC solution. This can be attributed to the fact that the NPs stayed deeper in the membrane since the MPD solution is the first reactant introduced for the IP reaction.

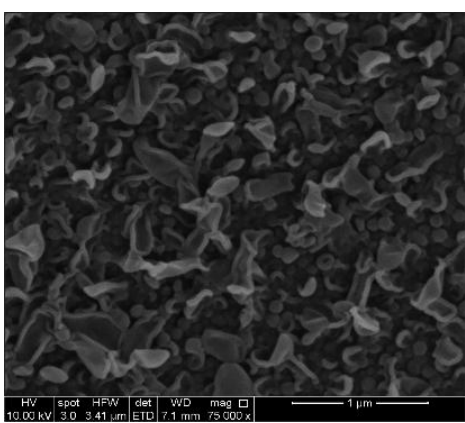

(a) $0 \% \mathrm{MCM}-41$

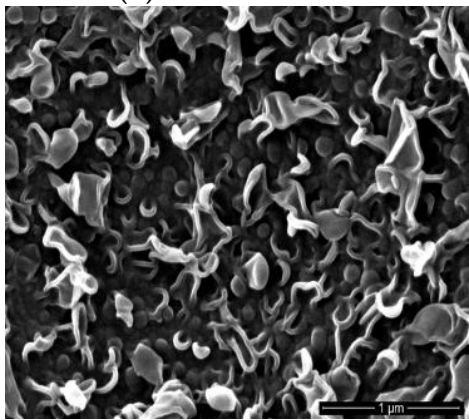

(d) $0.02 \%$ MCM-41 in TMC

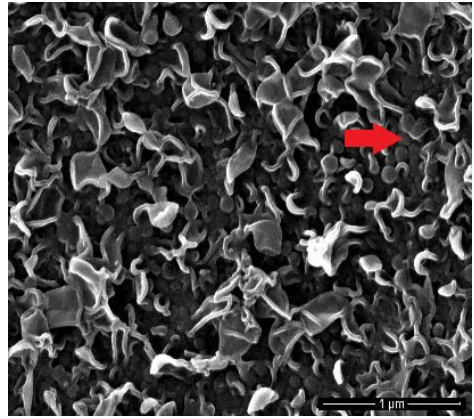

(g) $0.04 \%$ MCM-41 in TMC

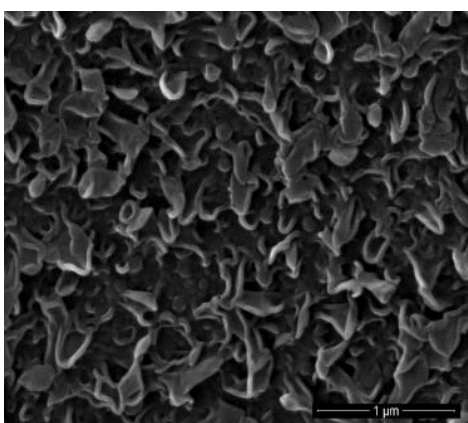

(b) $0.01 \%$ MCM-41 in TMC

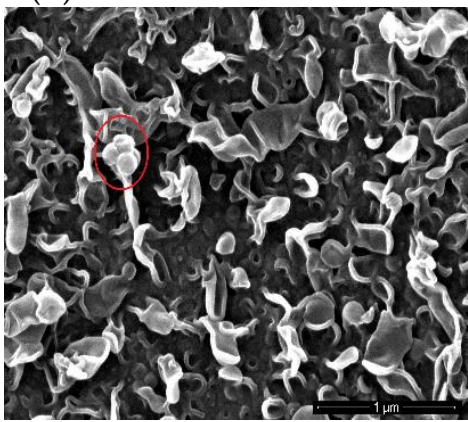

(e) $0.025 \%$ MCM-41 in TMC

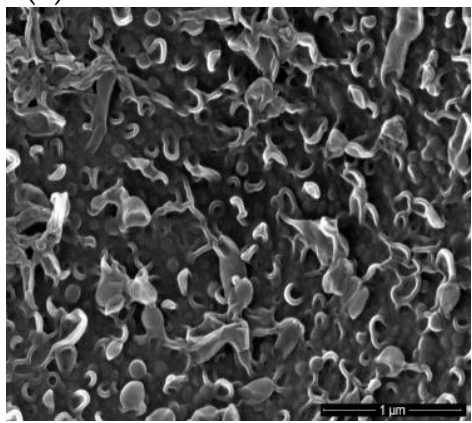

(h) $0.015 \%$ MCM-41 in MPD

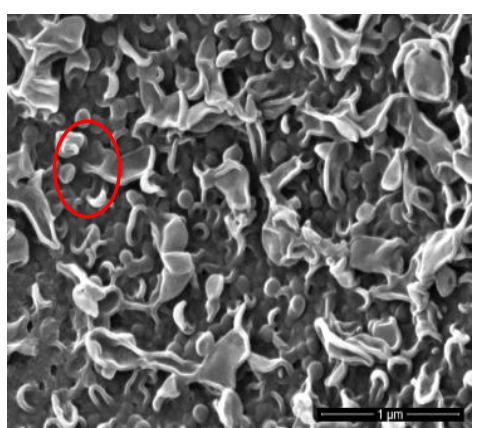

(c) $0.015 \%$ MCM-41 in TMC

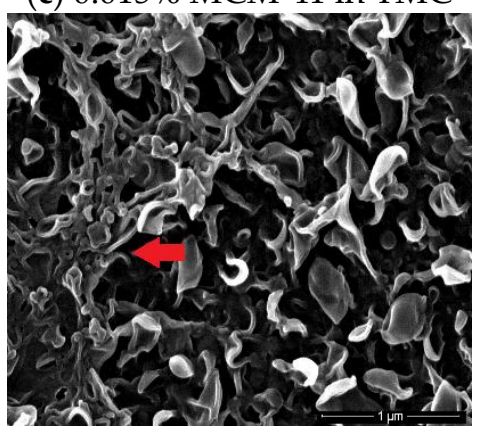

(f) $0.03 \% \mathrm{MCM}-41$ in TMC

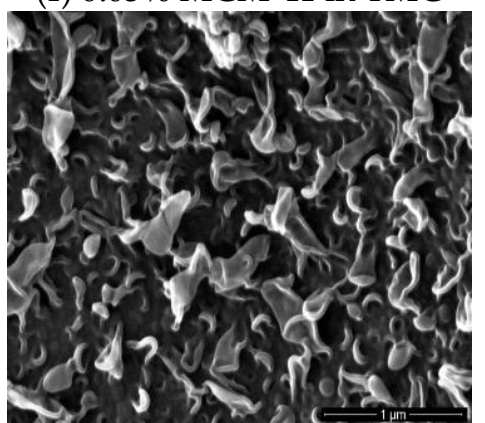

(i) $0.02 \% \mathrm{MCM}-41$ in MPD

Figure 2. SEM images for membranes with differently loaded NPs: (a) TFC; (b-g) NPs in TMC sol and (h-i) NPs in MPD sol.

Figure 3 shows the TEM images of the membrane made by embedding $0.02 \%$ silica NPs in MPD solution and $0.015 \%$ in TMC solution. The NPs are spherical in shape. It is clear that the particles went deeper inside the membrane layer when they were dispersed in the MPD solution, while they were closer to the surface when dispersed in the TMC solution. This is reasonable since the MPD solution is the first to be poured onto the PSU support layer. Apparently, adding the NPs to the MPD solution 
created a more stable structure. The thickness of the thin film layer was found to be 100-300 nm, which is somewhat thinner than the membrane previously developed in our group [8]. This difference results from a shorter polymerization time (15 s) used in this study than the previous one (120 s).

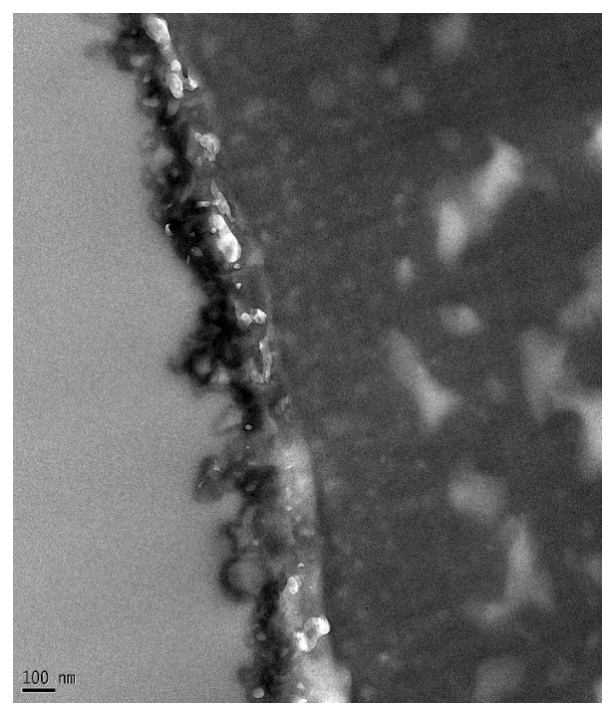

(a) $0.02 \%$ in MPD solution

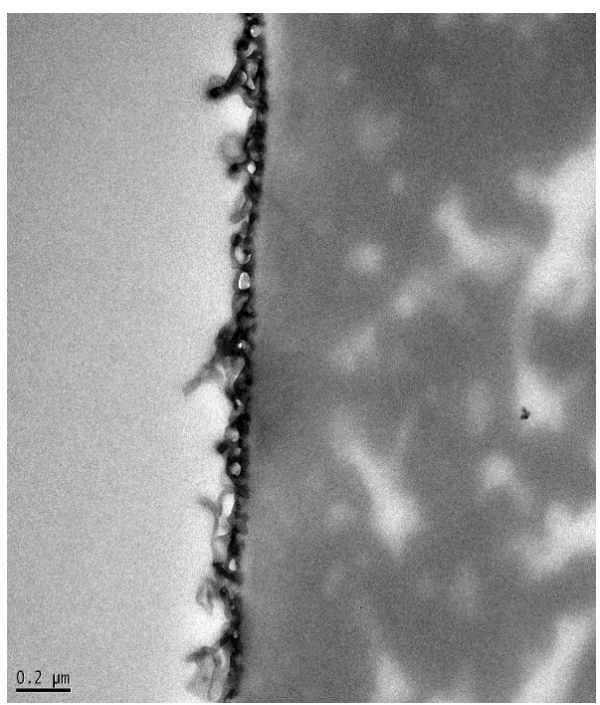

(b) $0.015 \%$ in TMC solution

Figure 3. TEM images of the membrane made by adding $0.02 \%$ NPs in MPD (a) and $0.015 \%$ NPs in $\mathrm{TMC}(\mathbf{b})$.

The contact angle measurements are presented in Figure 4. The contact angle was decreased from $54.9^{\circ}$ to $34.4^{\circ}$ and $28.0^{\circ}$ for the membranes embedding silica NPs in the TMC and MPD solutions, respectively. Generally, the membranes made from dispersing the NPs in the MPD solution had lower contact angles than the membranes made from dispersing the NPs in TMC. It is likely that the hydrophilic silica NPs disperse in the aqueous solution of MPD better than in the organic TMC solution, and there is less aggregation when dispersed in the aqueous phase. Dispersing the NPs in an MPD solution would place them deeper in the membrane, so the possibility of NP release would be lower.

The ATR FT-IR analysis is presented in Figure 5 a for the membranes made by dispersing MCM-41 NPs in TMC solution and in Figure $5 b$ for the membranes made by dispersing the NPs in MPD solution. Each also includes the spectra of PSU support layer and original TFC for comparison. Based on the literature, Si-OH stretching vibration is at approximately $950 \mathrm{~cm}^{-1}$ [32] and $\mathrm{Si}-\mathrm{O}-\mathrm{Si}$ vibration peak is at approximately $1050 \mathrm{~cm}^{-1}$ [24]. When the MCM-41 NPs were embedded at an increasing concentration, there appeared to have tiny peaks corresponding to silica at the highest concentrations, but was still too low to detect with certainty. The other peaks resulted from the PSU layer and TFC membrane chemical bonds. The main vibrations from the PSU were the symmetric and asymmetric $\mathrm{O}=\mathrm{S}=\mathrm{O}$ at 1150 and $1298-1325 \mathrm{~cm}^{-1}$, respectively. The carbon bond stretching peaks were at $1245 \mathrm{~cm}^{-1}$ for asymmetric $\mathrm{C}-\mathrm{O}-\mathrm{C}$ and $1488-1590 \mathrm{~cm}^{-1}$ for aromatic C-C $[33,34]$. The membrane thin film peaks came from the vibration of $\mathrm{C}=\mathrm{O}$ stretching (amide I) at $1660 \mathrm{~cm}^{-1}$ and $\mathrm{C}-\mathrm{N}$ stretching and $\mathrm{N}-\mathrm{H}$ bending (amide $\Pi$ ) at $1541 \mathrm{~cm}^{-1}$. In addition to that, $\mathrm{N}-\mathrm{H}$ and $\mathrm{C}=\mathrm{O}$ stretching peaks were observed at 1610 and $1490 \mathrm{~cm}^{-1}$, respectively [8,34-36]. 


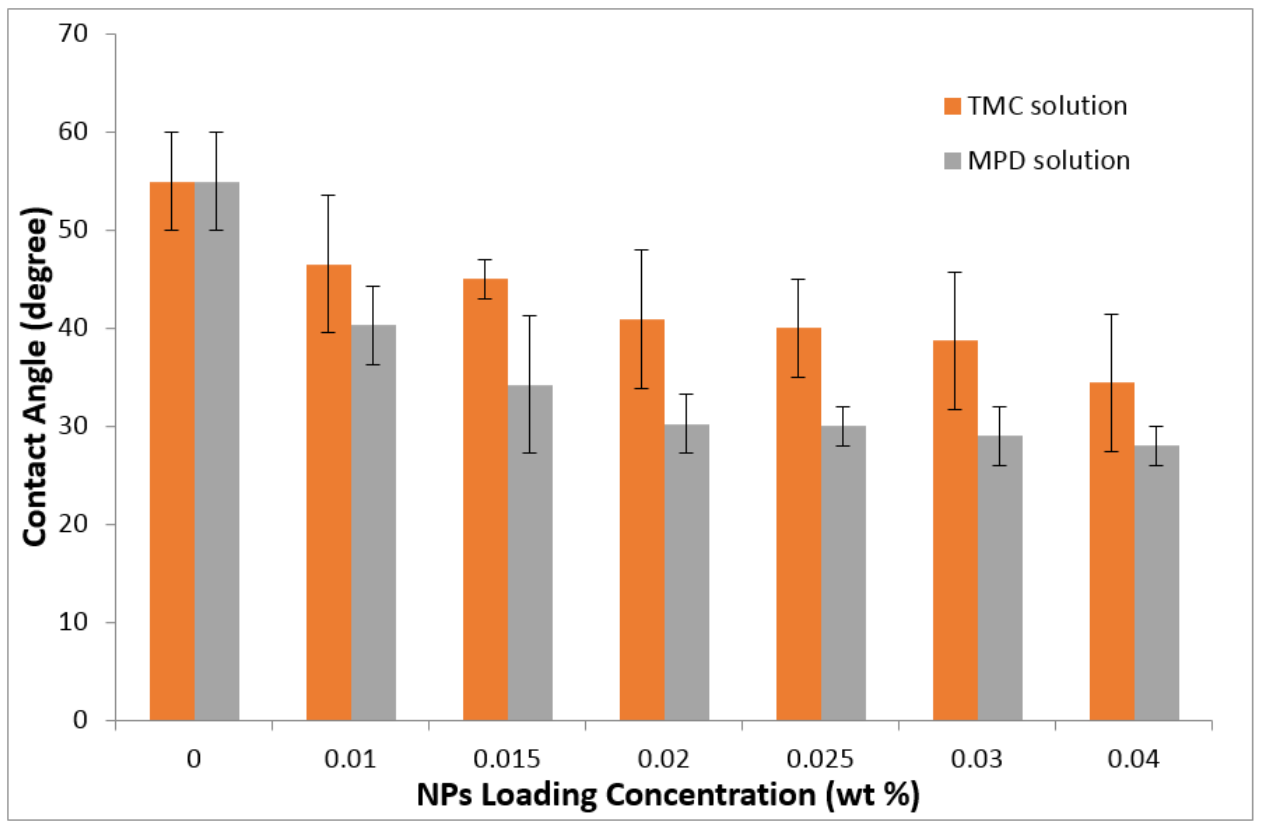

Figure 4. DI water contact angle.

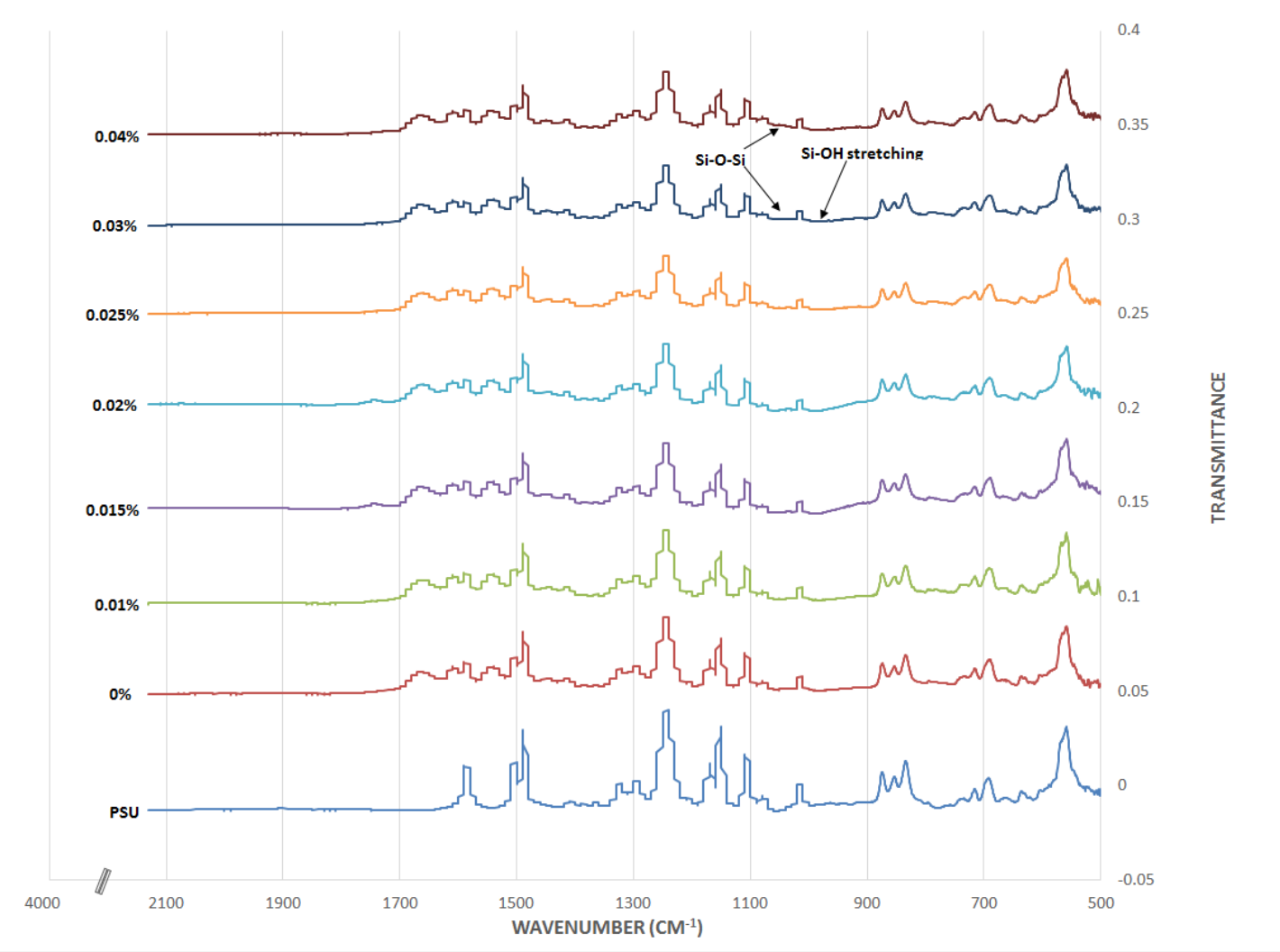

(a)

Figure 5. Cont. 


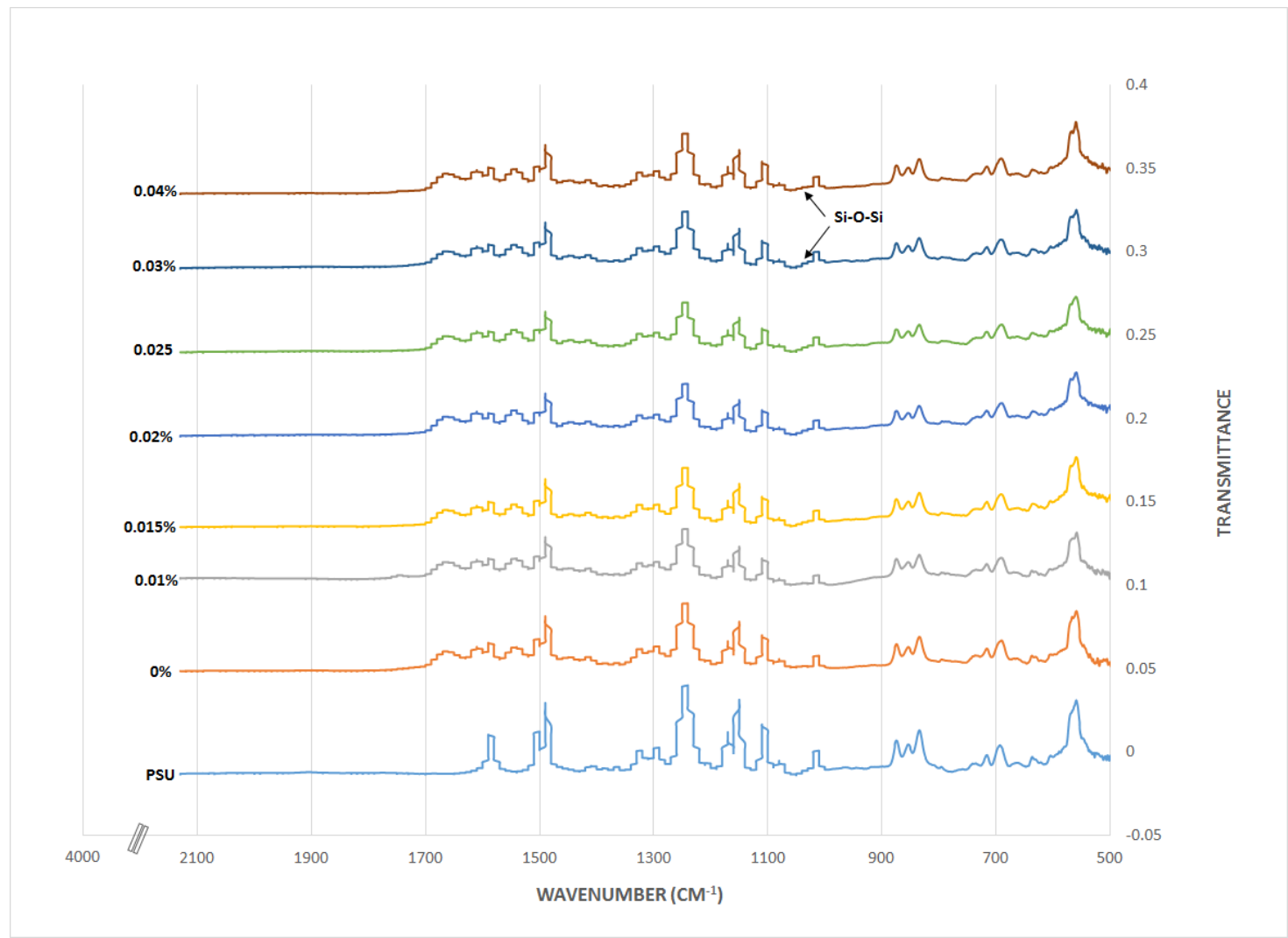

(b)

Figure 5. (a) Membrane's ATR FT-IR spectra from embedding NPs in TMC solution; (b) Membranes from embedding NPs in MPD solution.

\subsection{Membrane Salt Rejection and Water Flux}

The salt rejection and water flux of the TFC and TFN membranes were studied and presented in Figure 6a for filling MCM-41 NPs in TMC solution and Figure 6b for filling MCM-41 NPs in MPD solution. The system conditions were as follows: a $2000 \mathrm{ppm} \mathrm{NaCl}$ solution at $2068 \mathrm{kPa}$ and $25^{\circ} \mathrm{C}$. For the membrane prepared by dispersing MCM-41 NPs in the TMC solution (Figure 6a), the water flux increased as the NP percentage increased, while the salt rejection slightly decreased. The concentration range of NPs was $0 \%-0.04 \%$ for both solutions. The optimal loading of the silica NPs to TMC solution was $0.015 \%$, a condition under which the water flux was increased from 44.33 to $60.5 \mathrm{~L} / \mathrm{m}^{2} \cdot \mathrm{h}$ compared with the TFC membrane, while the rejection remained essentially the same (from 95.0\% to $94.6 \%$ ). Adding the NPs to the MPD solution had a comparable effect; under an optimal NP concentration of $0.02 \%$, the water flux increased from 44.33 to $64.1 \mathrm{~L} / \mathrm{m}^{2} \cdot \mathrm{h}$ in comparison with the TFC membrane, while the rejection was decreased from $95 \%$ to $94.1 \%$ (Figure 6b). Dispersion of NPs in the MPD solution yielded a slightly better and more stable result compared to the addition of NPs to the TMC solution. The effect of the NPs likely comes from the hydrophilic nature of the mesoporous silica, and a more hydrophilic surface may cause an increase in the water flux [8]. A slightly higher water flux associated with the addition of silica NPs to the MPD solution compared to the TMC organic solution is consistent with the contact angle measurements shown in Figure 3. Dispersing NPs in the MPD solution could also help place the NPs deeper into the membrane, resulting in a more stable structure. 


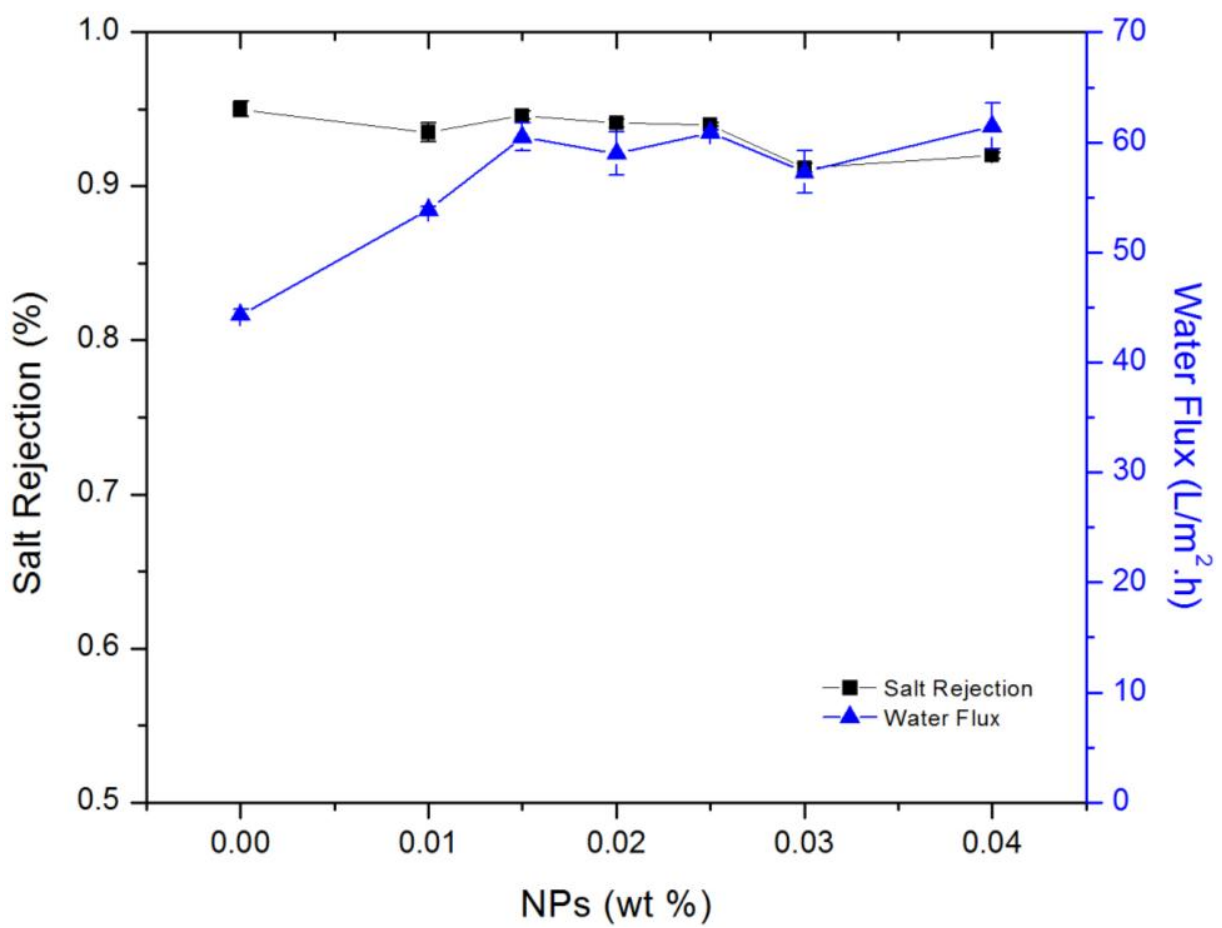

(a)

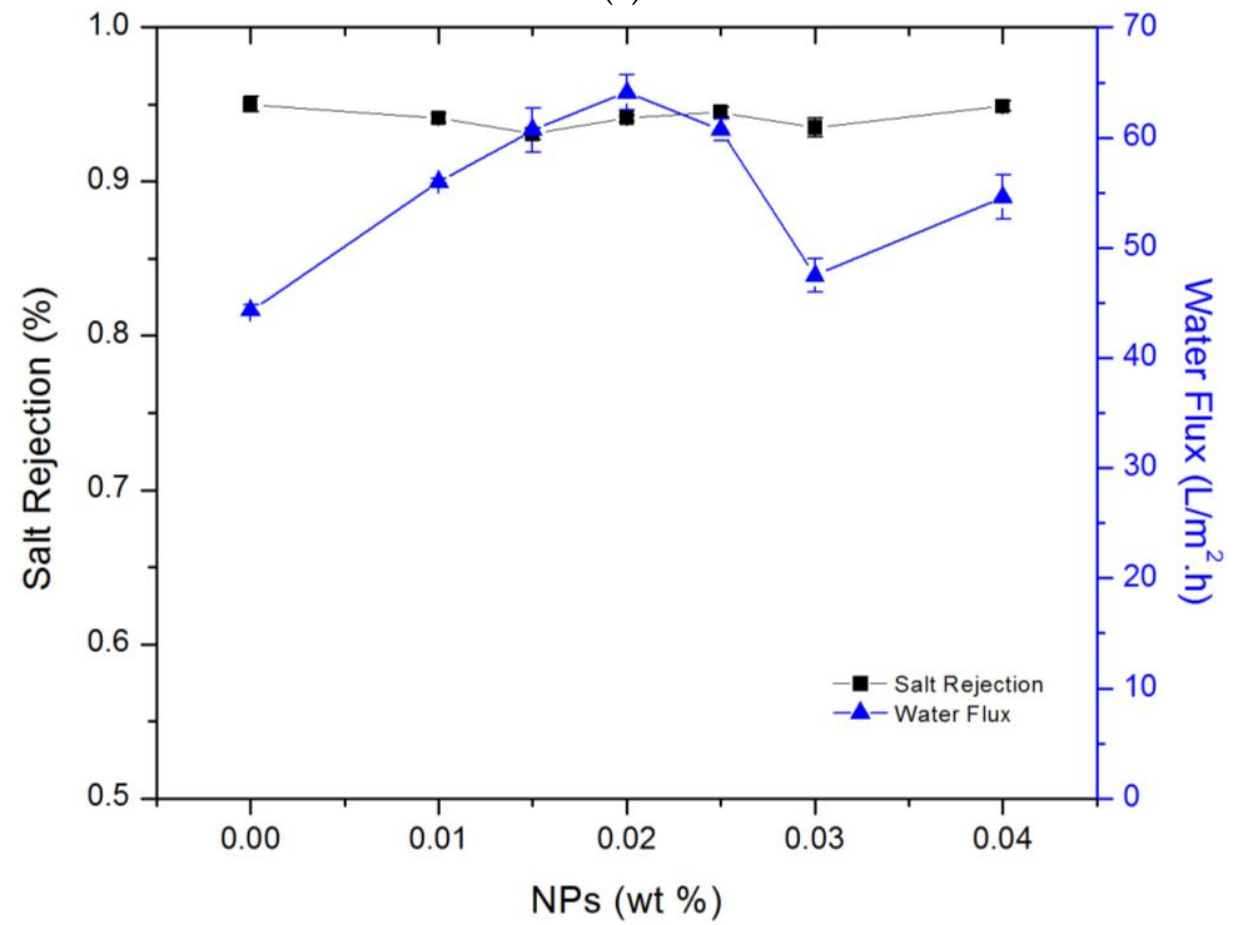

(b)

Figure 6. (a) Salt rejection and water flux for filling NPs in TMC solution; (b) Salt rejection and water flux for adding NPs to MPD solution, under operation conditions of $2068 \mathrm{kPa}$ and $25^{\circ} \mathrm{C}$.

To place our research in the context of other reported nanocomposite membranes, we tabulated the optimal solid loading, water permeability, and $\mathrm{NaCl}$ rejection in Table 2 for a number of nanocomposite membranes. The comparison indicated that the MCM-41 silica nanocomposite membranes had a rejection comparable to others but a significantly higher water flux. 
Table 2. A performance comparison of thin film nanocomposite (TFN) membranes.

\begin{tabular}{|c|c|c|c|c|}
\hline Nanofiller & Optimum Loading (wt \%) & $\begin{array}{c}\text { Water Permeability } \\
\left(\mathrm{L} / \mathrm{m}^{2} \cdot \mathbf{h} \cdot \mathbf{k P a}\right)\end{array}$ & $\mathrm{NaCl}$ Rejection \% & Reference \\
\hline MCM-41 & 0.02 & 0.0310 & $94.1 \pm 0.2$ & This work \\
\hline Graphene oxide & 0.015 & 0.0287 & $93.8 \pm 0.6$ & [37] \\
\hline Multi wall nanotubes & 0.1 & 0.0175 & $\sim 90$ & [38] \\
\hline Zeolite & 0.4 & 0.0137 & $93.9 \pm 0.3$ & [39] \\
\hline Silica & 0.6 & 0.0087 & 95.1 & {$[25]$} \\
\hline
\end{tabular}

\section{Conclusions}

Isooctane was used in this study as a TMC solvent due to its higher boiling point and lower volatility than hexane for thin-film composite preparation, showing no effect on membrane performance. A comparison was made between dispersions of MCM-41 silica NPs in MPD and TMC solutions. The results show that the performance of membranes made by dispersing the silica NPs in the MPD solution was slightly better than those made by dispersing the NPs in the TMC solution. At an optimal dosage of $0.02 \%$ MCM-41 NPs in the MPD solution, the water flux increased from 44.3 to $64.1 \mathrm{~L} / \mathrm{m}^{2} \cdot \mathrm{h}$, while the salt rejection decreased slightly from $95.0 \%$ to $94.1 \%$. At an optimal dosage of $0.015 \%$ MCM-41 NPs in the TMC solution, the water flux increased from 44.3 to $60.5 \mathrm{~L} / \mathrm{m}^{2} \cdot \mathrm{h}$ and the salt rejection remained essentially the same.

Acknowledgments: This study was supported by the Higher Committee for Education Development in Iraq (HCED-Iraq) through a scholarship to Mohammed Kadhom and the Missouri Water Resources Research Center. We would like to acknowledge Qingsong Yu in the Department of Mechanical and Aerospace Engineering at University of Missouri for the access to the video contact angle system and the Electron Microscopy Core (EMC) material, particularly Deana Grant for TEM sample preparation.

Author Contributions: All authors were involved in conceiving and designing the experiments; Mohammed Kadhom performed the experiments, analyzed the data, and wrote the first draft. All contributed to the data interpretation and preparation of the final paper.

Conflicts of Interest: The authors declare no conflict of interest.

\section{References}

1. Elimelech, M.; Phillip, W.A. The future of sea water desalination: Energy, technology, and the environment. Science 2011, 333, 712-717. [CrossRef] [PubMed]

2. Shaffer, D.L.; Yip, N.Y.; Gilron, J.; Elimelech, M. Seawater desalination for agriculture by integrated forward and reverse osmosis: Improved product water quality for potentially less energy. J. Membr. Sci. 2012, 415-416, 1-8. [CrossRef]

3. Ettouney, H.M.; El-Dessouky, H.T.; Faibish, R.S.; Gowin, P.J. Evaluating the economics of desalination. Chem. Eng. Prog. 2002, 98, 32-39.

4. Van der Bruggen, B.; Vandecasteele, C. Distillation vs. membrane filtration: Overview of process evolutions in seawater desalination. Desalination 2002, 143, 207-218. [CrossRef]

5. Cadotte, J.E. Interfacially Synthesized Reverse Osmosis Membrane. U.S. Patent 4,277,344, 7 July 1981.

6. Petersen, R.J. Composite reverse osmosis and nanofiltration membranes. J. Membr. Sci. 1993, 83, 81-150. [CrossRef]

7. Kim, E.S.; Kim, Y.J.; Yu, Q.; Deng, B. Preparation and characterization of polyamide thin-film composite membrane (PA-TFC) based on plasma-modified polyvinylidene fluoride (PVDF). J. Membr. Sci. 2009, 344, 71-81. [CrossRef]

8. Yin, J.; Kim, E.; Yang, J.; Deng, B. Fabrication of a novel thin-film nanocomposite (TFN) membrane containing MCM-41 silica nanoparticles (NPs) for water purification. J. Membr. Sci. 2012, 423-424, 238-246. [CrossRef]

9. Drelich, J.; Chibowski, E.; Meng, D.; Terpilowski, K. Hydrophilic and superhydrophilic surfaces and materials. Soft Matter 2011, 7, 9804-9828. [CrossRef]

10. Gaudin, A. Flotation; McGraw-Hill Book Company, Inc.: New York, NY, USA, 1957. 
11. Dong, H.; Zhao, L.; Zhang, L.; Chen, H.; Gao, C.; Ho, W.S.W. High-flux reverse osmosis membranes in corporate with NaY zeolite nanoparticles for brackish water desalination. J. Membr. Sci. 2015, 476, 373-383. [CrossRef]

12. Lind, M.L.; Ghosh, A.K.; Jawor, A.; Huang, X.; Hou, W.; Yang, Y.; Hoek, E. Influence of zeolite crystalsize on zeolite-polyamide thin film nanocomposite membranes. Langmuir 2009, 25, 10139-10145. [CrossRef] [PubMed]

13. Kong, C.L.; Shintani, T.; Tsuru, T. Pre-seeding assisted synthesis of a high performance polyamide-zeolite nanocomposite membrane for water purification. New J. Chem. 2010, 34, 2101-2104. [CrossRef]

14. Huang, H.; Qu, X.; Dong, H.; Zhang, L.; Chen, H. Role of NaA zeolites in the interfacial polymerization process towards a polyamide nanocomposite reverse osmosis membrane. RSC Adv. 2013, 3, 8203-8207. [CrossRef]

15. Huang, H.; Qu, X.; Ji, X.; Gao, X.; Zhang, L.; Chen, H.; Hou, L. Acid and multivalent ion resistance of thin film nanocomposite RO membranes loaded with silicalite-1 nanozeolites. J. Mater. Chem. A 2013, 1, 11343-11349. [CrossRef]

16. Dong, H.; Qu, X.Y.; Zhang, L.; Cheng, L.H.; Chen, H.L.; Gao, C.J. Preparation and characterization of surface-modified zeolite-polyamide thin film nanocomposite membranes for desalination. Desalin. Water Treat. 2011, 34, 6-12. [CrossRef]

17. Wang, R.; Hashimoto, K.; Fujishima, A.; Chikuni, M.; Kojima, E.; Kitamura, A.; Shimohigoshi, M.; Watanabe, T. Light-induced amphiphilic surfaces. Nature 1997, 388, 431-432. [CrossRef]

18. Emadzadeh, D.; Lau, W.J.; Matsuura, T.; Ismail, A.F.; Rahbari-Sisakht, M. Synthesis and characterization of thin film nanocomposite forward osmosis membrane with hydrophilic nanocomposite support to reduce internal concentration polarization. J. Membr. Sci. 2014, 449, 74-85. [CrossRef]

19. Yadaa, M.; Inouea, Y.; Akihitoa, G.; Nodab, I.; Torikaia, T.; Wataria, T.; Hotokebuchi, T. Apatite-forming ability of titanium compound nanotube thin films formed on a titanium metal plate in a simulated body fluid. Colloids Surf. B Biointerfaces 2010, 80, 116-124. [CrossRef] [PubMed]

20. Emadzadeha, D.; Laua, W.J.; Matsuura, T.; Hilal, N.; Ismail, A.F. The potential of thin film nanocomposite membrane in reducing organic fouling in forward osmosis process. Desalination 2014, 348, 82-88. [CrossRef]

21. Tettey, K.E.; Yee, M.Q.; Lee, D. Photocatalytic and conductive $\mathrm{MWCNT} / \mathrm{TiO}_{2}$ nanocomposite thin films. Appl. Mater. Interfaces 2010, 2, 2646-2652. [CrossRef] [PubMed]

22. Li, W.; Zhang, Y.; Li, Q.; Zhang, G. Metal-organic framework composite membranes: Synthesis and separation applications. Chem. Eng. Sci. 2015, 135, 232-257. [CrossRef]

23. Wu, H.; Tang, B.; Wu, P. Optimizing polyamide thin film composite membrane covalently bonded with modified mesoporous silica nanoparticles. J. Membr. Sci. 2013, 428, 341-348. [CrossRef]

24. Ma, X.; Lee, N.; Oh, H.; Hwang, J.; Kim, S. Preparation and characterization of silica/polyamide-imide nanocomposite thin films. Nanoscale Res. Lett. 2010, 5, 1846-1851. [CrossRef] [PubMed]

25. Tiraferri, A.; Kang, Y.; Giannelis, E.P.; Elimelech, M. Highly hydrophilic thin-film composite forward osmosis membranes functionalized with surface-tailored nanoparticles. Appl. Mater. Interfaces 2012, 4, 5044-5053. [CrossRef] [PubMed]

26. Jadav, G.L.; Singh, P.S. Synthesis of novel silica-polyamide nanocomposite membrane with enhanced properties. J. Membr. Sci. 2009, 328, 257-267. [CrossRef]

27. Cai, Q.; Luo, Z.; Pang, W.; Fan, Y.; Chen, X.; Cui, F.Z. Dilute solution routes to various controllable morphologies of MCM-41 silica with a basic medium. Chem. Mater. 2001, 13, 258-263. [CrossRef]

28. Hexane Safety Data Sheet, version 5.6; Product No. 139386; Sigma-Aldrich: St. Louis, MO, USA, 23 May 2016.

29. Hexane Safety Data Sheet; Cat No. AC326920000; Fisher Scientific: Pittsburgh, PA, USA, 2 April 2014.

30. Isooctane Safety Data Sheet, version 5.1; Product No. IRMM442; Sigma-Aldrich: St. Louis, MO, USA, 3 November 2015.

31. Isooctane Safety Data Sheet, version 1.5; Product No. 1116963; Chevron Phillips: The Woodlands, TX, USA, 17 May 2016.

32. Viart, N.; Niznansky, D.; Rehspringer, J.L. Structural evolution of a formamide modified sol—Spectroscopic study. J. Sol. Gel. Sci. Technol. 1997, 8, 183-187. [CrossRef]

33. Deng, H.; Xu, Y.; Chen, Q.; Wei, X.; Zhu, B. High flux positively charged nanofiltration membranes prepared by UV-initiated graft polymerization of methacrylatoethyl trimethyl ammonium chloride (DMC) onto polysulfone membranes. J. Membr. Sci. 2011, 366, 363-372. [CrossRef] 
34. Tarboush, B.J.A.; Rana, D.; Matsuura, T.; Arafat, H.A.; Narbaitz, R.M. Preparation of thin-film-composite polyamide membranes for desalination using novel hydrophilic surface modifying macromolecules. J. Membr. Sci. 2008, 325, 166-175. [CrossRef]

35. Lee, H.S.; Im, S.J.; Kim, J.H.; Kim, H.J.; Kim, J.P.; Min, B.R. Polyamidethin-film nanofiltration nanoparticles. Desalination 2008, 219, 48-56. [CrossRef]

36. Shawky, H.A.; Chae, S.-R.; Lin, S.; Wiesner, M.R. Synthesis and characterization of a carbon nanotube/polymer nanocomposite membrane for water treatment. Desalination 2011, 272, 46-50. [CrossRef]

37. Yin, J.; Zhu, G.; Deng, B. Graphene oxide (GO) enhanced polyamide (PA) thin-film nanocomposite (TFN) membrane for water purification. Desalination 2016, 379, 93-101. [CrossRef]

38. Zhao, H.; Qiu, S.; Wu, L.; Zhang, L.; Chen, H.; Gao, C. Improving the performance of polyamide reverse osmosis membrane by incorporation of modified multi-walled carbon nanotubes. J. Membr. Sci. 2014, 450, 249-256. [CrossRef]

39. Jeong, B.-H.; Hoek, E.M.V.; Yan, Y.; Subramani, A.; Huang, X.; Hurwitz, G.; Ghosh, A.K.; Jawor, A. Interfacial polymerization of thin film nanocomposites: A new concept for reverse osmosis membranes. J. Membr. Sci. 2007, 294, 1-7. [CrossRef]

(C) 2016 by the authors; licensee MDPI, Basel, Switzerland. This article is an open access article distributed under the terms and conditions of the Creative Commons Attribution (CC-BY) license (http://creativecommons.org/licenses/by/4.0/). 